\title{
Design and test of flexible chassis automatic tracking steering system
}

\author{
Song Shujie ${ }^{1,2}$, Li Yining ${ }^{3}$, Qu Jiwei ${ }^{3}$, Zhou Wei ${ }^{3}$, Guo Kangquann ${ }^{3,4^{*}}$ \\ (1. College of Food Science and Engineering, Northwest A\&F University, Yangling 712100, Shaanxi, China; \\ 2. College of Food Engineering and Nutritional Science, Shaanxi Normal University, Xi'an 710119, Shaanxi, China; \\ 3. College of Mechanical and Electronic Engineering, Northwest A\&F University, Yangling 712100, Shaanxi, China; \\ 4. Shaanxi Engineering Research Centre for Agricultural Equipment, Yangling 712100, Shaanxi, China)
}

\begin{abstract}
In order to develop an innovative omnidirectional non-homonymic flexible chassis (FC), the four-wheel steering control method of FC was designed by a new concept called off-centered steering (OCS) and the automatic tracking steering system was analyzed. Novelty of this wheel concept lies in the non-conventional positioning of the steering axis and wheel axis. Additionally, the steering axis of steerable wheel was motorized with an on/off electrometrical brake to overcome a hyper-motorization issue inherent to the wheel's geometrical properties and hold the steering position. Based on the off-centered steering characteristics of FC, the Wheatstone bridge was applied in the steering control system. The bridge resistances are used to track target steering angles and the actual steering angle, respectively. The output voltage of the bridge is exploited to adjust the wheel's speed so that steering and automatic tracking could be achieved. Experiments at different speeds, loadings, and target steering angles were conducted. Results showed that the chassis can indeed be controlled independently and its steering range is from $-90^{\circ}$ to $90^{\circ}$, which indicated the automatic tracking steering system was effective. The electromagnetic lock (EL) can significantly improve the stability of the chassis and reduce the vibration. Loading has no significant effect on the accuracy of the steering angle and the time it takes to complete steering tasks. The time taken to complete a forward steering task showed a linear relationship with the required angles, but was independent of rotation speed; for backward steering, time was related to both target angles and rotation speed. The results presented in this research may provide a reference for the steering control strategies of the four-wheel individual drive and four-wheel (4WID/4WIS) vehicle in the future.
\end{abstract}

Keywords: electric vehicles, flexible chassis, four-wheel steering, automatic tracking, control system DOI: $10.25165 /$ j.ijabe.20171005.2525

Citation: Song S J, Li Y N, Qu J W, Zhou W, Guo K Q. Design and test of flexible chassis automatic tracking steering system. Int J Agric \& Biol Eng, 2017; 10(5): 45-54.

\section{Introduction}

Electric vehicles (EVs) have garnered increasing

\section{Received date: 2016-04-13 Accepted date: 2016-12-04}

Biographies: Song Shujie, Lecturer, research interest: agricultural robotics and food processing equipment and machinery, Email: foodssj@snnu.edu.cn; Li Yining, PhD candidate, research interest: agricultural robotics, Email: liyining_work@163.com; Qu Jiwei, $\mathrm{PhD}$ candidate, research interest: agricultural robotics, Email: 738524407@qq.com; Zhou Wei, Master graduate candidate, research interest: agricultural robotics, Email: 614145334@qq.com.

* Corresponding author: Guo Kangquan, Professor, research interest: agricultural equipment and machinery. College of Mechanical and Electronic Engineering, Northwest A\&F University, Yangling 712100, Shaanxi, China. Tel: +86-2987088712,Email: jdgkq@nwsuaf.edu.cn. attention from researchers, developers, and consumers as a response to the global energy crisis $^{[1,2]}$. The four-wheel individual drive and four-wheel individual steering (4WID/4WIS) EV offers better driving efficiency, flexibility, and maneuverability by virtue of its wheels being independently driven and steered by electric motors instead of the traditional integrated driving system and steering mechanism ${ }^{[3]}$. The FC is a $4 \mathrm{WID} / 4 \mathrm{WIS}$ EV with in-wheel motors (IWM) that is suited to narrow roads within semi-closed or closed environments at low speed due to its omni-directional running capability.

Steering control has proven a challenging endeavor in terms of the 4WID/4WIS electric chassis. Existing single-wheel steering modes are based mainly on 
motor-assisting, either direct-steering by the motor and gear unit or by other devices connected to the steering motor. Many previous researchers have made valuable contributions to the literature in this field. For instance, Eze Corp Ltd. in Australia ${ }^{[4]}$, Kanazawa Institute of Technology ${ }^{[5]}$, Yokohama National University ${ }^{[6]}$, the University of Tokyo in Japan ${ }^{[7]}$, and Pusan National University $^{[8]}$ in Korea. There are several research institutions currently focusing on this method in China, as well, including Nanjing University of Aeronautics and Astronautics $^{[9]}$, the Advanced Robotics Laboratory at Chinese University of Hong Kong ${ }^{[10-13]}$, Shenzhen Automobile and Transportation Engineering Vocational and Technical College ${ }^{[14-17]}$, Jilin University ${ }^{[18-20]}$, School of Control Science and Engineering College ${ }^{[21-24]}$, Changsha University of Science and Technology ${ }^{[25,26]}$, and Southwest Jiaotong University ${ }^{[27]}$.

Any existing steering control methods for 4WIS/4WID EVs require that a steering motor should be used, either directly or indirectly, thus requiring a complex control circuit and preventing the EV from making any turn while moving. This research proposed an automatic tracking steering system based on an off-centered steering axis without using a steering motor. One of the two bridge arms provides the tracking signal of the target angle while the other arm allows IWM position tracking. IWM speed is controlled by the output voltage of the bridge, i.e., changes in the relative angle of the wheel and the chassis frame to facilitate automatic tracking steering.

\section{Mechanism and principle of automatic tracking steering}

FC, developed at Northwest A\&F University and shown in Figure 1, is symmetrical and is made of four independent articulations. FC's main technical parameters are listed in Table 1. Each articulation part combines an OCS axis, a pair of shock absorbers, an EL (FBD-050, from Taiwan KAIDE), and a DC brushless motor wheel (IWM from BATTLE, its main technical parameters are shown in Table 2), which has three degrees of freedom (DOF) (propulsion, direction and rotation). The OCS wheel plane is parallel to the steering axis but does not contain it. In addition, the steering axis and wheel axis intersect in one point. The leg can rotate $180^{\circ}$ round its attachment point (as shown in Figure 2). Once an articulation is placed at the right position, the system is designed to keep it in position with the use of an EL. A passive vertical suspension made of springs is used to connect the steerable wheels to the chassis, allowing the wheels to keep contact with the ground on uneven surfaces. FC can change its direction using differential steering, or by changing the direction of its articulations, making the chassis omni-directional and allowing it to move in tight areas (narrow environment). Many other configurations can be imagined and the 12 DOF on FC gives the chassis great flexibility and versatility in its locomotion capabilities.

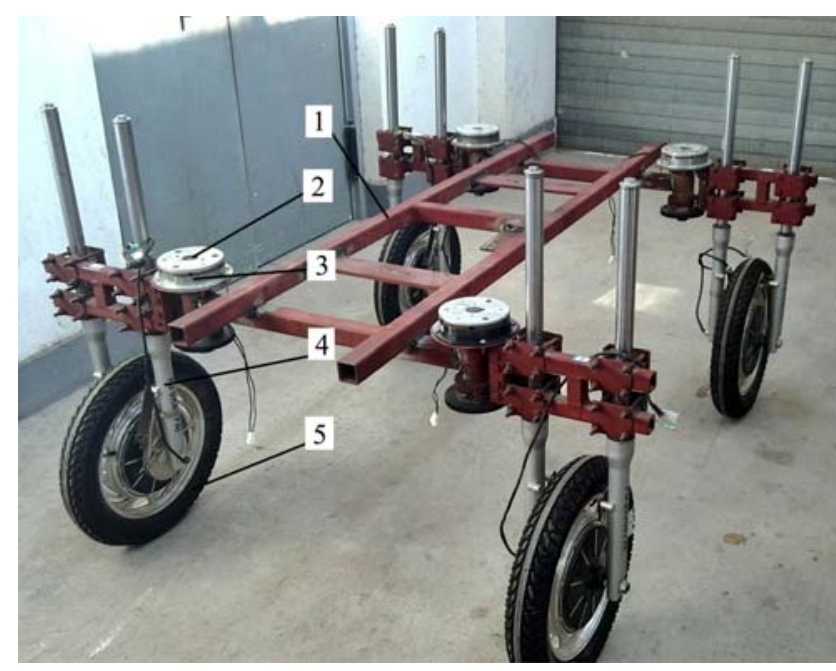

1. Chassis 2. Off-centered steering axis 3. EL 4. Shock absorber 5. IWM Figure 1 Flexible chassis sample vehicle



Figure 2 FC omni-direcitonal capabilities (top view)

Table 1 Main technical parameters of the flexible chassis

\begin{tabular}{lc}
\hline \multicolumn{1}{c}{ Technical parameters/Units } & Value \\
\hline Dimensions of $\mathrm{FC} / \mathrm{mm} \times \mathrm{mm} \times \mathrm{mm}$ & $1602.3 \times 1342.5 \times 705.8$ \\
Weight $/ \mathrm{kg}$ & 202.6 \\
Distance between empty frame to the ground $/ \mathrm{mm}$ & 580.7 \\
Lateral distance between the steering axis $/ \mathrm{mm}$ & 610.5 \\
Longitudinal distance between the steering axis $/ \mathrm{mm}$ & 1210.6 \\
Working speed $/ \mathrm{m} \cdot \mathrm{s}^{-1}$ & $0.5-3.6$ \\
Designed bearing weight $/ \mathrm{kg}$ & 200 \\
\hline
\end{tabular}


Table 2 Main technical parameters of the IWM and its tire

\begin{tabular}{lc}
\hline \multicolumn{1}{c}{ Technical parameters/Unit } & Value \\
\hline Rated power/W & 500 \\
Rated voltage/ $\mathrm{V}$ & 48.0 \\
Rotation speed range $/ \mathrm{r} \cdot \mathrm{min}^{-1}$ & $10-500$ \\
Adaptation tire size $/ \mathrm{mm} \times \mathrm{mm}$ & $160 \times 30$ \\
inflation pressure $/ \mathrm{MPa}$ & 0.15 \\
\hline
\end{tabular}

\subsection{Automatic tracking steering structure}

In order to minimize resistance to the steering structure, the conventional steering shaft is generally coplanar to the wheel rotation plane; an off-centered bias, conversely, leaves a certain distance $d$ from the wheel motion plane without using a steering motor (as shown in Figure 3). An off-centered automatic tracking bias device consists of an IWM, off-centered axis, and wheel supporting mechanism, pair of gears, an EL, and angle detector resistor. When the IWM rotates around the OCS axis, the gears rotate following the axis, driving the detection resistor $R_{1}$. The principle is that changes in resistance $R_{1}$ track the steering position of the IWM; a precision multi-turn potentiometer detects rotation angle resistance.

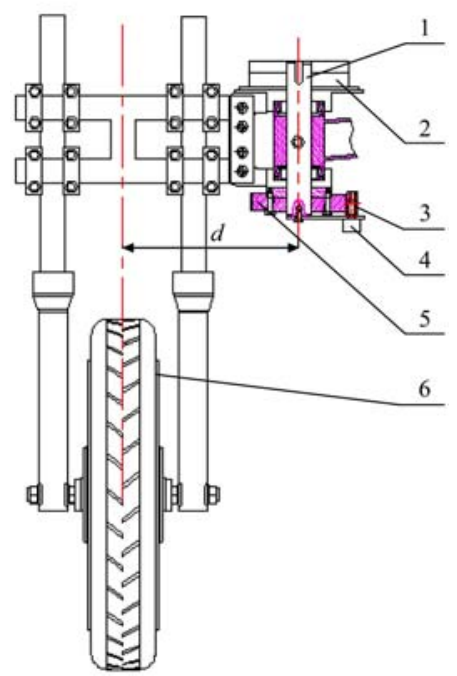

1. Off-centered axis 2. Electromechanical brake 3,5. Gears 4. Multi-turn potentiometer 6. IWM

Figure 3 Location tracking structure on off-centered wheel (front view)

\subsection{Determination of angle range}

According to the FC operation and road conditions, this study was mainly focused on the low-speed steering Ackerman principle in terms of determining the respective off-centered axis steering angle range in different motion situations. (The high-speed model, our other ostensible option, is not appropriate for the FC.)
The Ackerman-principle-based model is shown in Figure 4. Only the right-turn situation was analyzed here to save space, as right and left turns are symmetrical.

$O$ refers to the barycenter in an ideal state, $O^{\prime}$ refers to an instant turning center, $\alpha_{i}(i=1,2,3,4)$ is the steering angle of the $i^{\text {th }}$ off-centered wheel, $R_{i}(i=1,2,3,4)$ is the radial rotation of the wheel (for instant center), $R$ is the turning radius of the barycenter, $a$ and $b$ refer to the horizontal distance between the extended line of the instant center and front and rear axle, $W$ is tread, $L$ refers to the wheel base, $v_{i}(i=1,2,3,4)$ is the linear velocity of the $i^{\text {th }}$ wheel (for instant center), and $r$ is distance between the right wheel and instant center.

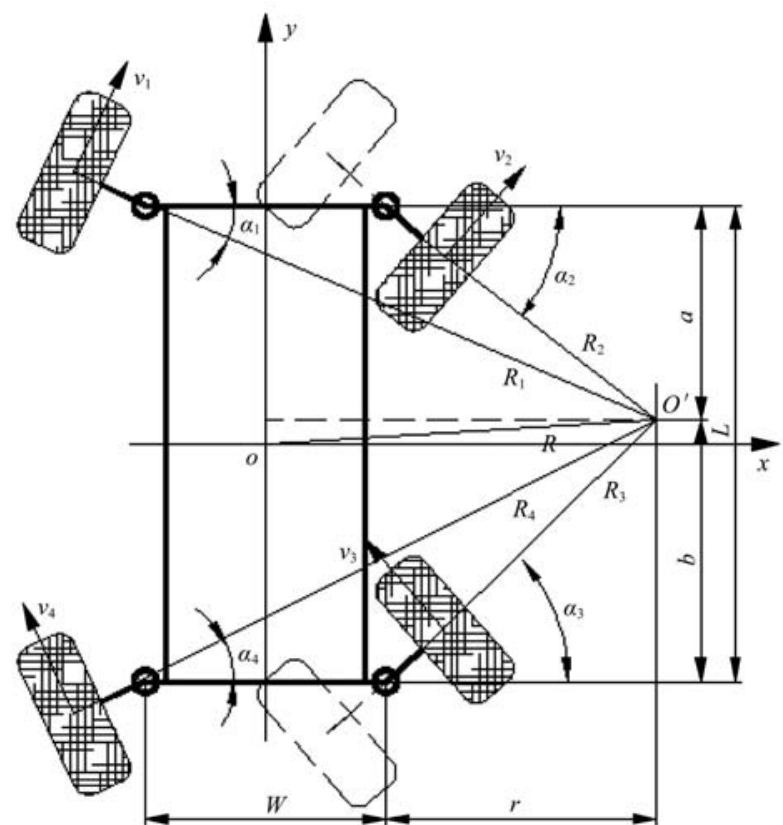

Figure 4 Low-speed steering model based on Ackerman steering principle

The geometric equations of the four-wheel steering angle are as follows:

$$
\left\{\begin{array}{c}
\alpha_{1}=\arctan \left(\frac{a}{r+W}\right) \\
\alpha_{2}=\arctan \left(\frac{a}{r}\right) \\
\alpha_{3}=\arctan \left(\frac{b}{r}\right) \\
\alpha_{4}=\arctan \left(\frac{b}{r+W}\right) \\
a+b=L
\end{array}\right.
$$

Taking into account the real-world steering situation, the value ranges of each parameter are:

$$
r \geq 0
$$




$$
\begin{aligned}
& 0 \leq a \leq L \\
& 0 \leq b \leq L
\end{aligned}
$$

When $r=0$, the chassis is in the pivot turn, and when $r=$ $+\infty$, the chassis moves in a parallel manner. Equation (1) shows that each wheel's steering angle range is:

$$
-90^{\circ} \leq \alpha_{i} \leq 90^{\circ}
$$

where, $i=1,2,3,4$.

\subsection{Principle of automatic steering}

The automatic tracking steering system based on a bridge circuit is shown in Figure 5. It mainly consists of a micro control unit (MCU), step motor, bridge circuit, IWM, and motor drive controller. When the FC wheels turn, the MCU controls the step motor to rotate to the desired angle, then bridge arm resistance $R^{2}$ is changed by the step motor creating imbalance in the bridge; the output of the bridge voltage and the signal controlled by the MCU are superimposed to cause the IWM to accelerate or decelerate. The EL is released so that the off-centered steering axis rotates around the frame structure, then the other arm bridge resistance $R_{1}$ changes with the rotation and the bridge is restored to balance. The output voltage of the steering bridge reflects the difference between the steering axis and the target position, and the difference is constantly fed back to the drive controller. The controller continuously adjusts the speed of wheel to follow the real-time balance position signal automatically. When the target angle is reached, the EL switches back on again.



Note: $R_{i}$ are bridge resistance and $i=1 / 2 / 3 / 4 . \quad R_{0}$ is the zero compensation resistors.

Figure 5 Automatic tracking steering schematics based on Wheatstone bridge
When bridge is balanced, the relationship between the resistances of four arms is:

$$
\begin{gathered}
R_{1}=R_{2}=R_{3}=R_{4}=\frac{R}{2} \\
U_{0}=\frac{R_{2} R_{4}-R_{1} R_{3}}{\left(R_{1}+R_{2}\right)\left(R_{3}+R_{4}\right)} U_{e}
\end{gathered}
$$

where, $R_{i}(i=1,2,3,4)$ is bridge resistance, $\Omega ; R$ is the total resistance of the potentiometer, $\Omega ; U_{e}$ is supply voltage, $\mathrm{V} ; U_{0}$ is output voltage, $\mathrm{V}$.

According to the analysis above, the steering angle range is $-90^{\circ}$ to $90^{\circ}$. The rotation angle of the stepping motor is $\theta$ and the transmission ratio of the gear is 10 , so $\theta$ ranges from $-900^{\circ}$ to $900^{\circ}$. Change in relative resistance at the potentiometer is calculated as follows:

$$
\Delta R=\frac{\theta}{360} \times \frac{R}{N}
$$

where, $N$ is the rated total number of turns and $0 \leq N \leq 10$.

Because the bridge is a half-bridge, $U_{0}$ can be integrated into Equation (2) to yield the following:

$$
U_{0}=\frac{\Delta R}{4 R_{i}+2 \Delta R} U_{e}=\frac{\Delta R}{2 R+2 \Delta R} U_{e}
$$

From Equations (1), (3) and (4), the relationship of stepper motor rotation angle $\theta$ and bridge output voltage $U_{0}$ can be written as follows:

$$
U_{0}=\frac{\theta}{7200+2 \theta} U_{e}
$$

Because $-900^{\circ} \leq \theta \leq 900^{\circ}$ and $U_{e}=5 \mathrm{~V},-0.833 \mathrm{~V} \leq U_{0} \leq$ $1.731 \mathrm{~V}$.

\section{Test bench for steering experiment}

To test the characteristics of the off-centered steering axis, we built a unique test bench based on the working characteristics of the driving wheel. The most notable feature of the bench was that the steering center of the off-centered shaft shared the same axis as the center of the horizontal turntable below the wheel to simulate its moving on the ground. The horizontal turntable was driven by the same IWM. Upper and lower coaxial structures ensured that the off-centered steering wheel module could be rotated freely along the upper shaft. A photo of the test bench is shown in Figure 6. 


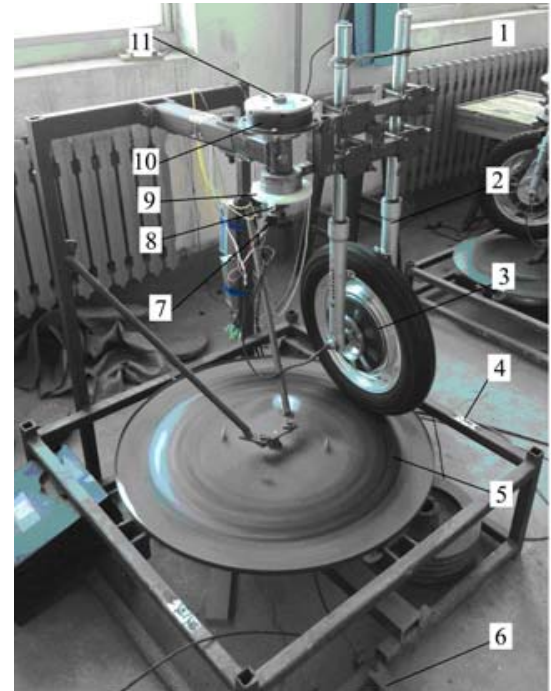

1. Loading 2. Support 3. IWM 4. Frame 5. Horizontal turntable 6. Brake 7. Positioner 8,9. Gears 10. Electromechanical brake 11. Off-centered axis

Figure 6 Test bench for off-centered steering module

\section{Control system design}

The core control module (CCM) of the off-centered steering module and its test bench was developed using STM32F103VET6 (STMicroelectronics). A diagram of the control system is shown in Figure 7. The rotation speed of the IWM based on the off-centered axis was controlled by superposition of the bridge and the core control signal; the superposition and amplification scheme is shown in Figure 8. According to the analysis in Section 1.3, the range of $U_{0}$ is $-0.833 \mathrm{~V}$ to $1.731 \mathrm{~V}$. In order to increase the sensitivity of the bridge circuit, the output voltage of the bridge was enlarged 5-fold then superimposed with the chip signal to control the IWM.

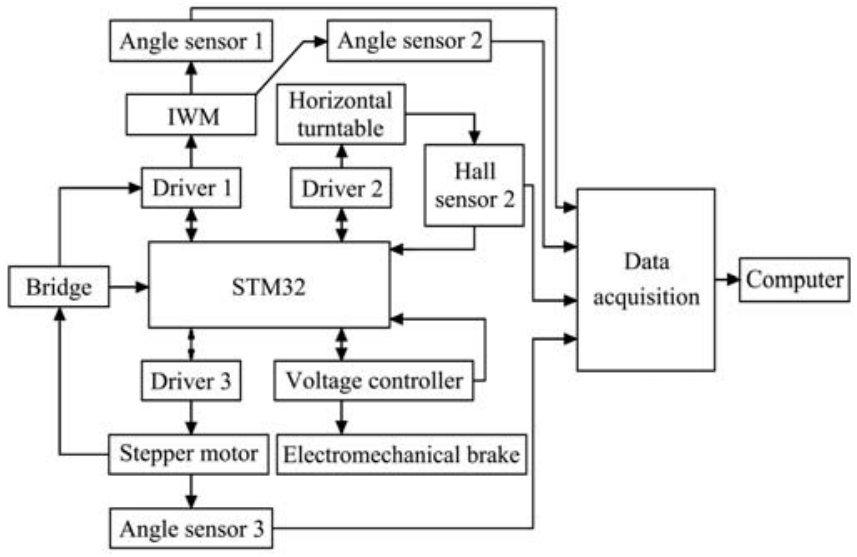

Figure 7 Steering control system

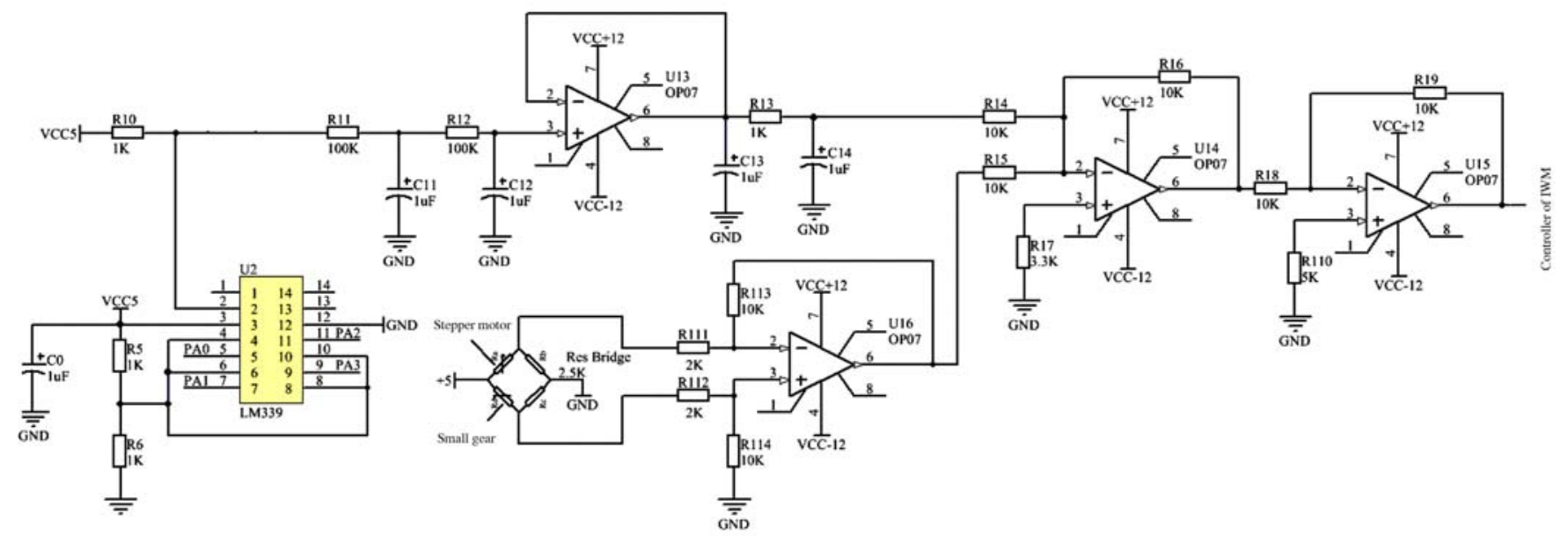

Figure 8 Bridge voltage amplification and superimposed scheme

The speed of the horizontal turntable was controlled by adjusting the Pulse Width Modulation (PWM) wave ${ }^{[29,30]}$ produced by the MCU via PID control algorithm. Using the same control method, an EL (FBD-050, Taiwan Cade KAIDE) was used to adjust the supply voltage of the chip. The data acquisition system consists of an industrial control computer $(610 \mathrm{H}$, Advantech Technologies) which stored data and a data acquisition card (PCI8326B, Beijing Zhongtai Research Ltd). An angle sensor (WDS35D-4, An Zhou Electronics Ltd) was used to measure the signal of the off-centered axis angle.

\section{Results and analysis}

\subsection{The EL test}

The tightening torque of the EL controlled the steering along the axis and its rotation speed. In order to determine the working law of EL, a standard torque sensor (ZRN501B, Beijing ZRN Instrument Technology Co., Ltd) was installed coaxial with the EL to test the relationship of supply voltage and static tightening torque. Different voltages were applied to the EL to detect the 
maximum torque that caused the EL to rotate. Each value was measured in five replicates; the averaged results obtained are shown in Figure 9.

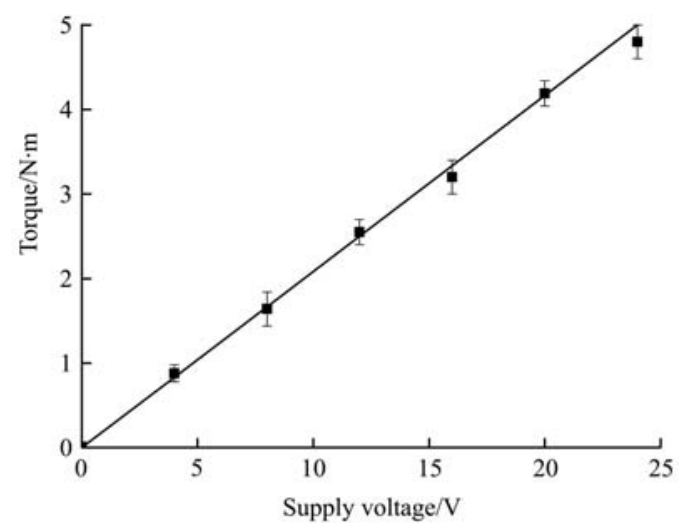

Figure 9 Relationship between supply voltage and EL static torque

By fitting the data in Figure 9, the relations can be obtained $\left(R^{2}=0.997\right)$ :

$$
T_{L}=0.051 U_{e}+0.201
$$

where, $T_{L}$ is the static tightening torque, $\mathrm{N} \cdot \mathrm{m} ; U_{e}$ is supply voltage, $\mathrm{V}$.

According to the literature [33], the relationship of steering force and loading is:

$$
F_{Z}=0.0844 N_{T}+36.095
$$

where, $F z$ is the steering force, $\mathrm{N} ; N_{T}$ is the loading weight, $\mathrm{N}$.

When the IWM rotates at uniform speed, then:

$$
T_{L}=F_{Z} d
$$

where, $d$ is the off-centered distance, $\mathrm{m}$.

By combining the equations above, the relationship between the loading weight and supply voltage can be obtained:

$$
U_{e}=0.363 N_{T}+150.98
$$

Then the supply voltage can be determined by the loading.

\subsection{Influence of electromagnetic EL on steering stabilization}

In order to examine the effects of the EL on the steering stability, comparison tests were conducted with or without locking the EL. The experimental conditions were as follows: no loading, target steering angle of $\pm 30^{\circ}$, and speed of $60 \mathrm{r} / \mathrm{min}$.

The EL was unlocked after setting the target steering angle and while the stepper motor rotated. Unlocking voltage was calculated via Equation (11). At the locking moment, the output voltage of the bridge was 0 and the voltage of EL was set to $24 \mathrm{~V}$.

Figure 10 shows the curves of the steering angle with and without locking of EL. Locking did not affect the steering process. Without locking, the steering shaft began to shake at $0^{\circ}$ and $\pm 30^{\circ}$; when the EL was working, there was almost no vibration in the steering shaft. In short, steering with locking was necessary.
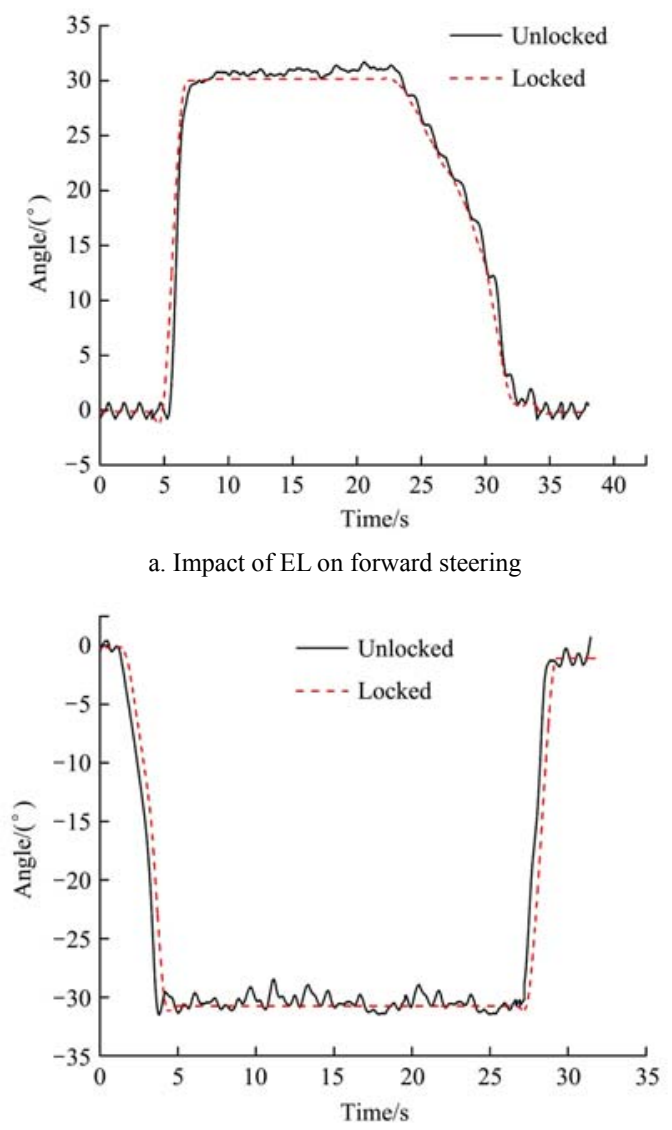

b. Impact of EL on backward steering

Figure 10 Impact of EL on steering

\subsection{Effect of loading on steering angle}

We tested various loading conditions to account for the fact that in real-world application, the FC sometimes must work under a load. The test conditions were as follows: no loading, $300 \mathrm{~N}$ and $500 \mathrm{~N}$, respectively, at target angle of $\pm 30^{\circ}$, basic speed of $60 \mathrm{r} / \mathrm{min}$, and EL switched on with locking force which changed as the load changed.

Figure 11 shows the test results and Table 3 shows the average angles and the time taken for the steering task. Loading apparently had no effect on the accuracy of the corner steering, and only a limited impact on the time taken for steering. The basic speed, i.e., initial steering 
speed, and the speed changing process did not change under different loads. At different target angles, the time taken for steering varied while the steering process was fairly consistent.



a. Impact of loading on forward steering

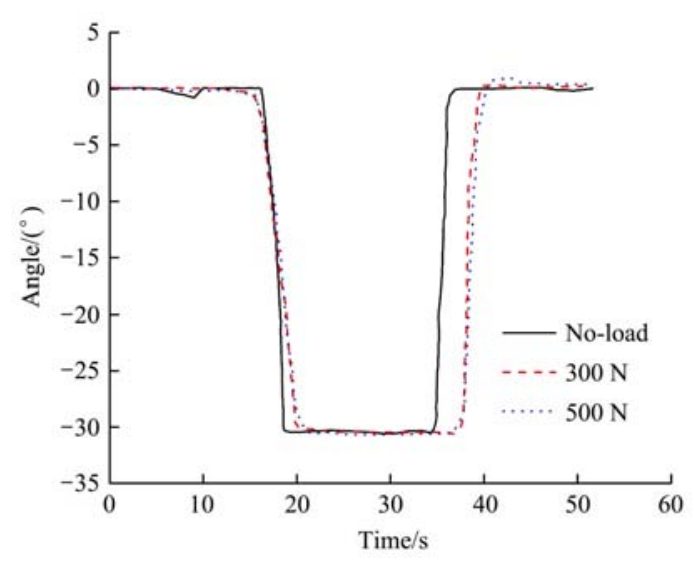

b. Impact of loading on backward steering

Figure 11 Impact of loading on steering

Table 3 Results of steering angles based on loading

\begin{tabular}{ccccc}
\hline $\begin{array}{c}\text { Target } \\
\text { angle } /\left({ }^{\circ}\right)\end{array}$ & Loading/N & $\begin{array}{c}\text { Average } \\
\text { angle/( }\left(^{\circ}\right)\end{array}$ & $\begin{array}{c}\text { Absolute } \\
\text { Error } /\left(^{\circ}\right)\end{array}$ & Time/s \\
\hline \multirow{3}{*}{30} & 0 & 30.39 & 0.39 & 3.148 \\
& 500 & 30.41 & 0.41 & 3.286 \\
& Average value & 30.31 & 0.31 & 3.043 \\
& Standard deviation & 0.053 & 0.37 & 3.159 \\
& 0 & -30.29 & -0.29 & 3.195 \\
& 300 & -30.36 & -0.36 & 3.574 \\
& 500 & -30.42 & -0.42 & 3.645 \\
& Average value & -30.36 & -0.36 & 3.472 \\
& Standard deviation & 0.065 & & 0.242 \\
\hline
\end{tabular}

Figure 12 shows the tire trend and its footprint when different test loading was applied. The contact area of tire footprint increased with test loading increasing. And due to the steering of wheel, But the footprint is asymmetric but is biased in favor of one side of the steering axis.

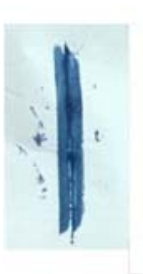

No loading

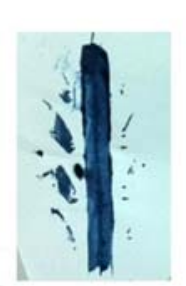

$300 \mathrm{~N}$

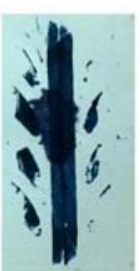

$500 \mathrm{~N}$

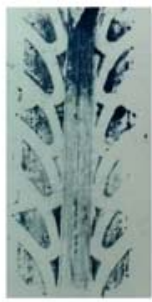

Full print

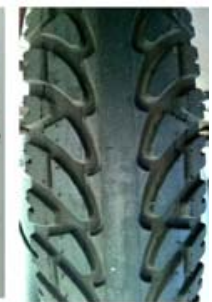

Tire trend
Figure 12 Tire trend and its footprint with different test loadings

\subsection{Effect of speed on the steering angle}

The chassis turns at a certain speed named the "basic speed" of the IWM. In order to analyze the influence of basic speed on steering angle, further tests with varying basic speed was conducted. The test conditions were: no loading, target angle of $\pm 30^{\circ}$, basic speeds of $30 \mathrm{r} / \mathrm{min}$, $60 \mathrm{r} / \mathrm{min}, 90 \mathrm{r} / \mathrm{min}$ and $120 \mathrm{r} / \mathrm{min}$, and $\mathrm{FC}$ speed range of $30-120 \mathrm{r} / \mathrm{min}$.

The test results are shown in Figure 13. It took about 3-4 s to reach target angle of $+30^{\circ}$, where the accuracy of the angle was stable and independent of basic speed. The reason for this is that the speed changing process was stable with the fixed bridge output voltage. Basic speed had greater impact on negative target angles then positive ones: It took about $2 \mathrm{~s}$ to reach a target angle of $-30^{\circ}$, for example. With fixed bridge output voltage and lower basic speed, the chip voltage and output voltage of the bridge were superimposed to less than zero, so the IWM speed dropped to $0 \mathrm{r} / \mathrm{min}$, the horizontal turntable dragged the IWM, so the steering efficiency was low, i.e., steering took more time. With quicker basic speed (120 r/min, for instance) the chip voltage and output voltage of the bridge were superimposed to above zero, so the IWM also rotated and steering efficiency was higher.

\subsection{Test of different target steering angles}

The steering angle range of each wheel in the FC is $-90^{\circ}$ to $+90^{\circ}$. Another experiment with different target angles was conducted under the following test conditions: target angles of $\pm 30^{\circ}, \pm 60^{\circ}$ and $\pm 90^{\circ}$, no loading, and basic speeds of $30 \mathrm{r} / \mathrm{min}, 60 \mathrm{r} / \mathrm{min}, 90 \mathrm{r} / \mathrm{min}$ and $120 \mathrm{r} / \mathrm{min}$.

Because the processes observed with varying basic speeds were similar, we only analyzed the test results gathered at $60 \mathrm{r} / \mathrm{min}$. Figure 14 shows the curve of different steering angles at $60 \mathrm{r} / \mathrm{min}$. The automatic tracking results were consistently favorable regardless of 
target angle.

The results of the tests on different basic speeds with different target angles are shown in Table 4. When steering forward the target angle was positive and when steering backward the target angle was negative. Although the basic speeds were different, the angle error was quite small. With fixed target angle, the time taken for steering was relatively fixed.

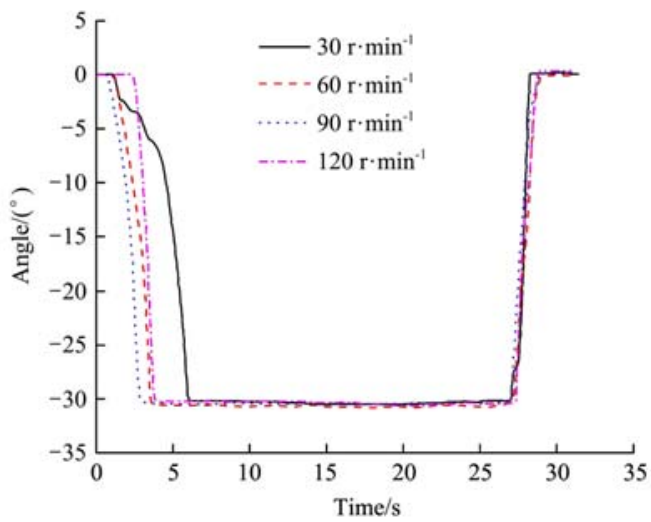

b. Impact of basic speed on backward steering

Figure 13 Impact of speed on steering without EL

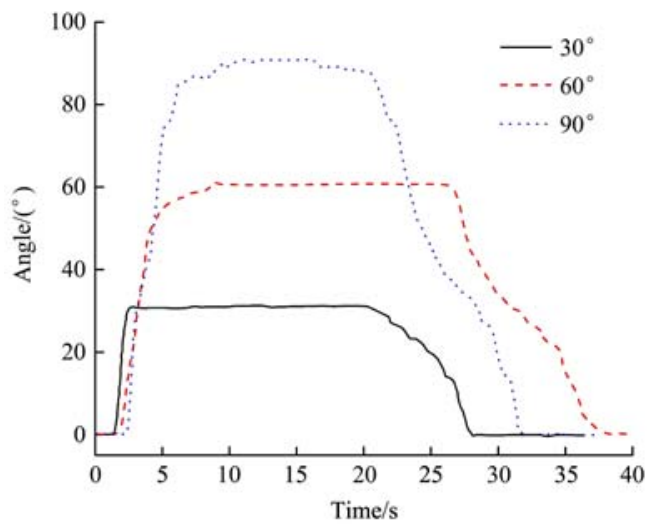

a. Forward steering test

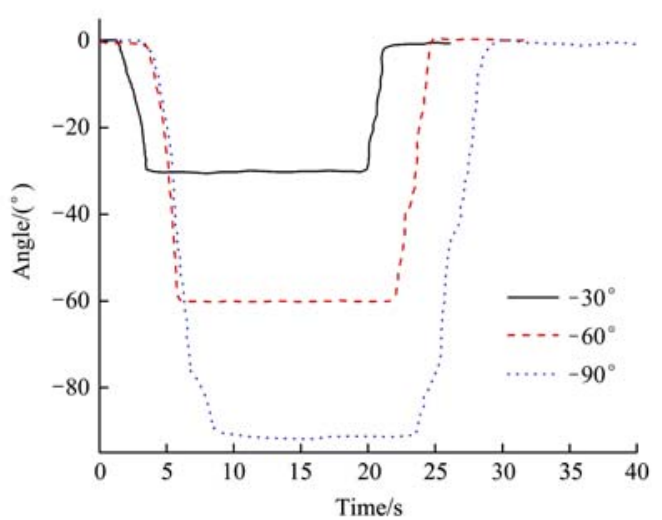

b. Backward steering test

Figure 14 Testing different steering angles

Table 4 Results of steering angle tests

\begin{tabular}{|c|c|c|c|c|c|c|c|c|c|}
\hline $\begin{array}{c}\text { Target } \\
\left.\text { angle/ } /{ }^{\circ}\right)\end{array}$ & $\begin{array}{l}\text { Loading } \\
\text { /N }\end{array}$ & $\begin{array}{l}\text { Average } \\
\text { angle } /\left(^{\circ}\right)\end{array}$ & $\begin{array}{l}\text { Absolute } \\
\text { Error/ }\left(^{\circ}\right)\end{array}$ & Time/s & $\begin{array}{c}\text { Target } \\
\text { angle/( }\left(^{\circ}\right)\end{array}$ & $\begin{array}{l}\text { Loading } \\
\text { /N }\end{array}$ & $\begin{array}{l}\text { Average } \\
\text { angle } /\left(^{\circ}\right)\end{array}$ & $\begin{array}{l}\text { Absolute } \\
\text { Error } /\left(^{\circ}\right)\end{array}$ & Time $/ \mathrm{s}$ \\
\hline \multirow{5}{*}{+30} & 30 & 30.14 & 0.14 & 3.087 & \multirow{5}{*}{-30} & 30 & -30.14 & 0.14 & 3.870 \\
\hline & 90 & 30.23 & 0.23 & 3.104 & & 90 & -30.20 & 0.20 & 2.064 \\
\hline & 120 & 30.32 & 0.32 & 3.906 & & 120 & -30.12 & 0.12 & 2.034 \\
\hline & Average value & 30.27 & & 3.311 & & Average value & -30.19 & & 2.791 \\
\hline & Standard deviation & 0.1086 & & 0.397 & & Standard deviation & 0.0763 & & 0.900 \\
\hline \multirow{5}{*}{+60} & 30 & 60.23 & 0.23 & 8.043 & \multirow{5}{*}{-60} & 30 & -60.23 & 0.23 & 4.867 \\
\hline & 60 & 60.43 & 0.43 & 7.945 & & 60 & -60.37 & 0.37 & 3.794 \\
\hline & 90 & 60.12 & 0.12 & 7.988 & & 90 & -60.34 & 0.34 & 2.625 \\
\hline & 120 & 60.34 & 0.34 & 8.123 & & 120 & -60.12 & 0.12 & 2.662 \\
\hline & Average value & 60.36 & & 8.025 & & Average value & -60.39 & & 3.487 \\
\hline \multirow{6}{*}{+90} & 30 & 88.43 & -1.57 & 11.403 & \multirow{6}{*}{-90} & 30 & -88.23 & -1.77 & 5.987 \\
\hline & 60 & 88.65 & -1.35 & 11.507 & & 60 & -88.98 & -1.02 & 4.724 \\
\hline & 90 & 88.23 & -1.77 & 11.608 & & 90 & -88.54 & -1.46 & 3.967 \\
\hline & 120 & 88.38 & -1.62 & 11.612 & & 120 & -88.75 & -1.25 & 3.924 \\
\hline & Average value & 88.17 & & 11.532 & & Average value & -88.63 & & 4.651 \\
\hline & Standard deviation & 1.021 & & 0.0991 & & Standard deviation & 0.319 & & 0.964 \\
\hline
\end{tabular}


The relationship between the target angle and time taken for steering was linear during forward steering, as shown in Figure 15. Linear fitting analysis was applied accordingly $\left(R^{2}=0.993\right)$ :

$$
t_{A}=0.1308 \theta_{A}-0.1745
$$

where, $t_{A}$ is the time taken to steer to the target angle, s; $\theta_{A}$ is the forward steering angle, rad.

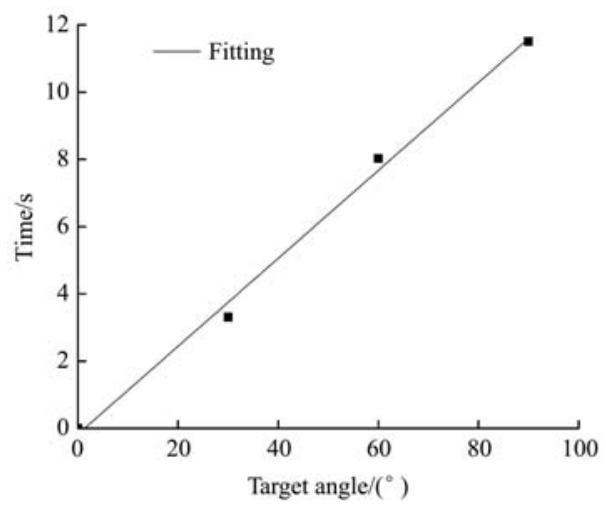

Figure 15 Time taken to steer forward versus target angle

The relationship between target angle, time taken for steering, and basic speed was linear, so a two-factor linear analysis was applied $\left(R^{2}=0.963\right)$ :

$$
t_{M}=-0.0308 \theta_{M}-0.0337 n+4.0727
$$

where, $t_{M}$ is the time taken to steer to the target angle, s; $\theta_{M}$ is the backward steering angle, $\left({ }^{\circ}\right) ; n$ is rotation speed, $\mathrm{r} / \mathrm{min}$.

To verify Equations (11) and (12), a comparison between the calculated values and test values at $100 \mathrm{r} / \mathrm{min}$ with a target angle of $\pm 10^{\circ}$ and at $70 \mathrm{r} / \mathrm{min}$ with a target angle of $\pm 45^{\circ}$ was established, as shown in Table 5. The results indicated that the relative error was small, i.e., those Equations (11) and (12) fit the data very well.

Table 5 Steering angle test results

\begin{tabular}{ccccc}
\hline $\begin{array}{c}\text { Target } \\
\text { angle } /\left({ }^{\circ}\right)\end{array}$ & $\begin{array}{c}\text { Rotation } \\
\text { Speed } / \mathrm{r} \cdot \mathrm{min}^{-1}\end{array}$ & $\begin{array}{c}\text { Calculated } \\
\text { time/s }\end{array}$ & Test time/s & $\begin{array}{c}\text { Relative } \\
\text { Error/\% }\end{array}$ \\
\hline-45 & 70 & 3.010 & 3.105 & 3.16 \\
-10 & 100 & 1.011 & 1.042 & 3.07 \\
+10 & 100 & 1.134 & 1.094 & 3.53 \\
+45 & 70 & 5.712 & 5.701 & 0.19 \\
\hline
\end{tabular}

\section{Conclusions}

From literature review, any existing steering control methods for 4WIS EV require steering motors either directly or indirectly, thus requiring a complex control circuit or preventing the EV from making any turn while moving. Automatic tracking steering system for FC does not need any steering motors and could make turns while running.

The most notable conclusions of this study can be summarized as follows:

1) A new steering method was developed based on an off-centered structure and bridge circuit, and a unique test bench was designed to test the steering process.

2) The angle range of the off-centered steering axis is $-90^{\circ}$ to $90^{\circ}$.

3) Utilizing an EL can significantly improve the stability of the FC's steering process and reduce the vibration.

4) Loading has no significant effect on the accuracy of the steering angle and the time it took to complete steering tasks.

5) During forward steering, the time taken to steer is speed-independent and is linear only with the target angle; while during backward steering, time has a relationship with both basic speed and target angle.

\section{Acknowledgements}

This work was supported by the National Natural Science Foundation of China (Grant No. 51375401). We would also like to thank all the postgraduate students who provided valuable laboratory work and other support to this study.

\section{[References]}

[1] Lu D, Guo K Q. Divert cal motion model of flexible chassis. Journal of Agricultural Mechanization Research, 2011; 33(4): 219-222. (in Chinese)

[2] Lu D. Research and development for flexible chassis and its control system of conservatory work machines. Master's dissertation. Yangling: Northwest A\&F University, 2011. (in Chinese)

[3] Qiu Y J. Status quo and development of farm produce processing industry in China. Agricultural Science \& Technology and Equipment, 2009; 1: 71-72, 75. (in Chinese)

[4] Corp E. Smart-wheel Technology. 2002.

[5] Oshima H, Tani M, Kobayashi N, Ishii A, Imai K. Control for four-wheel individual steering and four-wheel driven electronic vehicle. Electrical Engineering in Japan, 2005; 153(3): 71-78.

[6] Ando N, Fujimoto H. Yaw-rate control for electric vehicle with active front/rear steering and driving/braking force 
distribution of rear wheels. 11th IEEE International Workshop on Advanced Motion Control, 2010.

[7] Wang Y, Nam K, Fujimoto H, Hori Y. Robust roll and yaw integrated control using 4 wheel steering based on yaw moment and lateral force observers. IEEJ Research Information, 2011; 134: 25-30. (in Japanese)

[8] Choi M W, Park J S, Lee B S, Lee M H. The performance of independent wheels steering vehicle (4WS) applied Ackerman geometry. 2008 ICCAS International Conference on Control, Automation and Systems, 2008.

[9] Zhang J, He X M. $360^{\circ}$ four-wheel steering electric car design. Highways \& Automotive Applications, 2007; 1: 1-4. (in Chinese)

[10] Lam T, Qian H, Xu Y. Direct yaw moment control for four wheel independent steering and drive vehicles based on centripetal force detection. IEEE International Conference on Robotics and Automation (ICRA), 2012.

[11] Lam T L, Qian H H, Xu Y S, Xu G. Omni-directional steer-by-wire interface for four wheel independent steering vehicle. IEEE Int Conf Robot, 2009; pp.1655-1660.

[12] Lam T L, Xu Y S, Xu G Q. Traction Force Distribution on Omni-directional Four Wheel Independent Drive Electric Vehicle. IEEE Int Conf Robot, 2009; pp.1661-1666.

[13] Lam T L, Qian H, Xu Y. Omnidirectional Steering Interface and Control for a Four-Wheel Independent Steering Vehicle. IEEE/ASME Transactions on Mechatronics, 2010; 15(3): 329-338.

[14] Ren S, Dong Z, Qiu H, Li Z, Qi Z T. Parameterization analysis for a four in-wheel-motors drive and four wheels independent steering electric vehicle based on multi-body inverse kinematics. International Journal of Biomechatronics and Biomedical Robotics, 2013; 2(2-4): 124-134.

[15] Deng Z J, Dong Z R. Research on stability simulation for four-wheel independent steering Electric Vehicle. Advanced Materials Research, 2012; 512-515: 2657-2661.

[16] Deng Z, Qi Z T, Dong Z R, He P, Han C W, Ren S Y. A road surface identification method for a four in-wheel-motor drive electric vehicle. International Journal of Biomechatronics and Biomedical Robotics, 2013; 2(2-4): 87-92.

[17] Zhu X, Qiu H, Dong Z, Qi Z T, Zhang Y. Steering coordination control of front wheels for a four in-wheel-motor drive electric vehicle. International Journal of Biomechatronics and Biomedical Robotics, 2013; 2(2-4): 75-80.

[18] Zong C F, Liu J W, Zheng H Y, Song P, Zhang Q. Modeling and special conditions simulation of electric vehicle with 4WID/4WIS. Automotive Engineering, 2011; 33(10): 829-833. (in Chinese)

[19] Liu J W. Study on stability integrated control algorithm of driving/steering/braking systems for four-wheel-independent electric vehicle. $\mathrm{PhD}$ dissertation. Changchun: Jilin University, 2012. (in Chinese)
[20] Chen G Y. Research on experiment platform of by-wire electric vehicle with four wheels independent control and its integrated chassis control strategy. $\mathrm{PhD}$ Dissertation. Changchun: Jilin University, 2012. (in Chinese)

[21] Yang F G, Ruan J H, Li Y B, Rong X W, Qiu X Y, Yin Z F. 4WID- 4WIS vehicle yaw control based on fuzzy logic control of AFS+ARS+DYC. Transactions of the CSAM, 2011; 42(10): 6-12. (in Chinese)

[22] Yang F G. Research on anti-skid and yaw stability control of 4WID/4WIS electrical vehicle. PhD dissertation. Jinan: Shandong University, 2010. (in Chinese)

[23] Ruan J H, Li Y B, Yang F G, Rong X W. Path tracking control of high-speed 4WID-4WIS autonomous vehicle. Robot, 2011; 33(4): 411-418, 433. (in Chinese)

[24] Ruan J H, Li Y B, Yang F G, Rong X W. Single-point preview control for unmanned high-speed 4WID-4WIS vehicle path tracking. Journal of Chongqing University: Natural Science Edition, 2011; 10: 21-26. (in Chinese)

[25] Qiu H, Lei Z B, Qi T Z M, Dong Z R. A novel design of a suspension system for Omni-directional electric vehicles. Advanced Materials Research, 2011; 308-310: 1826-1831.

[26] Qiu H, Qi T Z, Lei Z, Dong Z R. A novel design of an electric vehicle with lateral moving and in situ steering. 2011 Second International Conference on Mechanic Automation and Control Engineering (MACE), 2011.

[27] Li X P, Zhang Z T. Design, modeling and simulation of a novel Omni-directional steering system. 2013 2nd International Conference on Mechatronics and Control Engineering, ICMCE 2013.

[28] Yang L, Guo K Q, Ding X M. The steering control system design of flexible chassis for conservatory work based on bridge circuit. Journal of Agricultural Mechanization Research, 2013; 35(9): 151-155. (in Chinese)

[29] Chen W K, Chen Z, Wang Z, Gao Y W, Tian T, Gao Y X. Control system design of omni directional electric chassis. Transactions of the CSAM, 2013; 44(6): 19-23, 34. (in Chinese)

[30] Meng Q H, Xu J, Wang D F. Power system of electric vehicle driven by in-wheel motors. Transactions of the CSAM, 2013; 44(8): 33-37, 20. (in Chinese)

[31] Lu W, Guo K H, Zhang J W. Feed-forward integrated with fuzzy PID feedback current control algorithm in electric power steering. Transactions of the CSAM, 2010; 41(8): 10-15. (in Chinese)

[32] Zhang W C, Zeng X J. Research on vehicle chassis dynamometer of MCG-200 based on fuzzy-PID. Transactions of the CSAM, 2006; 37(12): 17-19, 45. (in Chinese)

[33] Song S J, Qu J W, Li Y N, Guo K Q, Zhou W. Experiment on movement and dynamic property of driving wheel with offset steering shaft for agricultural vehicle. Transactions of the CSAE, 2015; 31(23): 28-34. (in Chinese) 